\title{
Prevalence of under nutrition and associated factors among female higher secondary students in the schools of costal block panchayat in Kerala
}

\author{
Raj Eliza S. ${ }^{1 *}$, Nisha R S. ${ }^{2}$, Philip S. ${ }^{3}$ \\ DOI: https://doi.org/10.17511/ijphr.2019.i2.02
}

1* Sharon Raj Eliza, Senior Resident, Department of Community Medicine, Government Medical College, Kottayam, Kerala, India.
$\mathbf{2}$ Nisha R S, Professor and Head, Department of Community Medicine, Government Medical College, Idukki, Kerala, India.
${ }^{3}$ Sairu Philip, Professor and Head, Department of Community Medicine, Government TD Medical College, Alappuzha, Kerala, India.

Introduction: The health status of an adolescent determines the health status in her adulthood. Adolescent girls in the age group 15-19 years are closer to their mother hood and thus the low birth weight girls become the next generation of stunted mothers thus, perpetuating the vicious cycle of malnutrition. Objectives: 1) To determine the prevalence of under nutrition among female higher secondary students in the schools of Ambalapuzha block. 2) To determine the factors associated with under nutrition. Methods: Cross- sectional study was conducted among higher secondary female students in the schools of Ambalapuzha Block. Sample size was calculated using the formula $\mathrm{Za} \mathrm{a}^{2} \mathrm{PQ} / \mathrm{L}^{2}$ (Za $-1.96, \mathrm{P}-33, \mathrm{Q}-67 \mathrm{~L}-12 \%$ of $\mathrm{P}$ ). Considering design effect (1.5) and $10 \%$ nonresponse, 559 adolescents were studied. Stratified and cluster sampling method was used. Information was collected using semi structured questionnaire. Weights and heights were measured and body mass index calculated and compared with Tim Cole anthropometric standards. Results: Prevalence of under nutrition was found to be $45.8 \%$.Factors associated with undernutrition were Hindu religion, nuclear family, father manual laborer or fisher man and absence of media influence on nutrition. Father being a manual laborer or fisherman was found to be an independent predictor of under nutrition. Conclusion: Prevalence of under nutrition was found to be high among female higher secondary students in Ambalappuzha Block

Keywords: Nutritionl value, Adolescence, Nutritional deficiencies

Corresponding Author

Sharon Raj Eliza, Senior Resident, Department of Community Medicine, Government Medical College, Kottayam, Kerala, India.

Email: sharoneliza123@gmail.com
How to Cite this Article

Eliza SR, Nisha RS, Philip S. Prevalence of under nutrition and associated factors among female higher secondary students in the schools of costal block panchayat in Kerala. Public Health Rev Int J Public Health Res. 2019;6(2):53-60.

Available From

https://publichealth.medresearch.in/index.php/ijphr/ article/view/100

\section{To Browse}

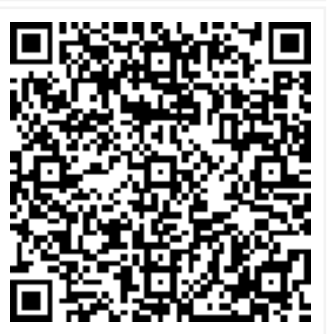

Manuscript Received 2019-03-05

Conflict of Interest No

C 2019 by Sharon Raj This is an Open Acc

Review Round 1 2019-03-15

Review Round 2
2019-03-21
$\begin{aligned} & \text { Ethical Approval } \\ & \text { Yes }\end{aligned}$

Review Round 2

Yes

\section{Review Round 3 \\ Plagiarism X-checker $8 \%$}

Accepted 2019-03-25

Note 


\section{Introduction}

Adolescence, a period of transition between childhood and adulthood, occupies a crucial position in the life of human beings [1]. About $21 \%$ of Indian population is adolescents [2]. Adolescent girls, constitutes nearly one tenth of Indian population and form a crucial segment of the society [3].

They are the future of the nation, forming a major demographic and economic force. Chronic undernutrition that causes stunting among young people delays growth and physical maturation, decreases the capacity to learn and to work [4].

Adolescent girls in the group 15-19 years are closer to their mother hood and thus in the absence of effective nutritional interventions, the low birth weight girls become the next generation of stunted mothers, thus, perpetuating the vicious cycle of malnutrition. Nutritional deficiencies increase the risks that girls and young women face during pregnancy and childbirth [5].

An accurate and valid data is required regarding the girth of the problem before initiation of prevention and control measures. Lack of regular, representative national surveys and variations in the adopted methodologies preclude accurate intercountry and intra-country comparisons [6].

There is a lacuna in studies conducted in Kerala on the under nutrition status of their adolescent females based on National Institute of Nutrition (NIN) definition of under nutrition and association between domestic violence and undernutrition.

Ambalappuzha is a coastal Block Panchayat in central Kerala which mainly constitutes poor fisherman families. There are more number of females than males with female to male ratio 1041 [7]. It constitutes the field area of Urban Health Training Centre which is under the Department of Community Medicine, Government T D Medical College, Alappuzha.

The present study tries to find out the prevalence of under nutrition among the late adolescent females of Ambalappuzha Block Panchayant which consists mainly of fisherman community and the factors responsible for this.

\section{Objectives}

01 . To determine the prevalence of under nutrition among female higher secondary students in the schools of Ambalapuzha Block Panchayat.
02. To determine the factors associated with undernutrition among female higher secondary students in schools of Ambalapuzha Block Panchayat

\section{Methodology}

Study Design: cross- sectional study

Study Population:Higher secondary female students in the schools of Ambalapuzha Block Panchayat.

Sample Size: According to the NFHS 3 data the prevalence of malnutrition among female youth(1524 years ) in Kerala was about $33 \%$ and prevalence of undernutrition among 15-19 year age group Indian females was $46.8 \% 8$.The sample size calculated using the formula Za2PQ/L2 is 337.( $\mathrm{Za}$ $-1.96, P-33, Q-67 L-12 \%$ of $P$ ). Considering design effect (1.5) and $10 \%$ non - response rate, the minimum sample size was found to be 557.A total of 559 adolescents were studied.

Sampling Method: stratified and cluster sampling. There are 9 higher secondary schools in Ambalapuzha block divided into 3 strata -5 govt, 2 govt-aided and 2 private. Total number of female higher secondary students in the 5 govt school is 450 (90 in each school), 2 govt aided schools is 900 (450 in each school) and in the 2 private school is 50 ( 25 in each school).

Total number of female higher secondary students in Ambalappuzha block $=1400$. Sample size required is 557. To get a proportionate sample from govt, govt aided and private school, number of students to be taken from govt school $=450 / 1400 * 557=$ 179 , from govt aided school $=900 / 1400 * 557=359$ and from private school $=50 / 1400 * 557=20$.

To get the required sample size, all female higher secondary students from 2 govt schools, 1govt aided school and 1 private school was chosen. Schools were taken as clusters. The schools were chosen randomly by lottery method. All the female higher secondary students in the selected school was enrolled into the study

Study Procedure: Information was collected from the adolescents using the semi structured questionnaire. Weights were determined using a platform weighing scale in kilograms. Height was measured using a no stretchable measuring tape in metres.

The body mass index was be calculated. Data was 
Entered into Excel sheet and analysed using appropriate software. Qualitative variables was expressed as proportions/percentages and quantitative variables as mean with standard deviation.

The association between undernutrition and risk factors was checked using the Pearson Chi square test. Students $T$ test was used to compare the mean BMI between different groups. Binary logistic regression analysis was done to find out independent predictors of undernutrition among higher secondary students of Ambalappuzha Block.

\section{Results}

A cross sectional study was conducted to estimate the prevalence of undernutrition and the factors associated among higher secondary female students in the schools of Ambalappuzha Block Panchayat.

Platform weighing scale and non-stretchable measuring tape was used to measure weight and height respectively of the adolescent and Body Mass Index was calculated using the formulae

Body mass index $(\mathrm{BMI})=\underline{\text { Weight }}(\underline{\mathrm{Kg}})$.

$$
\text { Height2 (meters) }
$$

According to the Tim Cole Anthropometric standard recommended by the National Institute of Nutrition, Hyderabad, an adolescent is considered to be under nourished if the Body Mass Index is less than 5th percentile for that particular age and sex.

General characteristics of the study subjects, family characteristics, health profile, food intake frequency and utilization of community nutrition services, substance use, influence of media on dietary intake and domestic violence was inquired using selfprepared semi structured questionnaire.

\section{Prevalence of Under nutrition in the study participants}

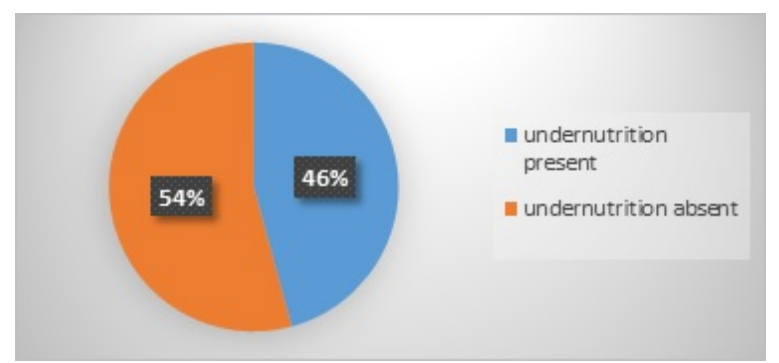

Figure-1: Prevalence of under nutrition in the study participants $(n=559)$
The prevalence of undernutrition among adolescent girls in the present study was found to be $45.8 \%$ Mean age of study participants was 16.57 years. Among the study subjects undernutrition was maximum in the age group 17-18

Bivariate Analysis: Bivariate analysis was done to find out factors associated with undernutrition in the study subjects. The study participants were divided into 2 groups-presence or absence of under nutrition, based on Tim Cole anthropometric standards. Those study subjects whose weight was less than 5th percentile for that particular age was considered undernourished.

Accordingly 256 (45.8\%) of them were found to be undernourished. The outcome variable was undernutrition. Pearson Chi square test was used. $p$ value was considered significant if $p<0.05$. Students $T$ test was also used to compare mean BMI in different groups.

The independent general characteristics that were analyzed are

01. Religion

02. Socioeconomic status

03. Type of school:

04. Family type and number of members in the family

05. Birth order

06. Parental relationship

07. Occupational and educational profile of parents

08. Acute and chronic disease

09. Whether deworming done in the last 6 months

10. Bowel habits

11. Menstrual flow and cycle regularity

12. Preference of type of food- grouped as vegetarian or mixed diet.

13. Food frequency

14. Non availability of food at home

15. Intake of iron and folic acid tablets

16. Utilization of supplementary nutrition from anganwadi

17. Influence of media on dietary habits

18. Whether facing domestic violence

When Chi square test was applied the following factors were found to be significantly associated 
With undernutrition.

01. Religion

02. Type of family

03. Number of members in the family

04. Father's occupation

05. Presence or absence of chronic disease

06. Influence of media

Table-1: Factors associated with under nutrition in the study subjects

\begin{tabular}{|c|c|c|c|c|}
\hline Variable & $\mid \begin{array}{l}\text { Undernutriti } \\
\text { on present }\end{array}$ & $\begin{array}{c}\text { Undernutriti } \\
\text { on absent }\end{array}$ & $\begin{array}{c}\text { Chi } \\
\text { square } \\
\text { value }\end{array}$ & \begin{tabular}{|c}
$\mathbf{P}$ \\
value
\end{tabular} \\
\hline \multicolumn{5}{|l|}{ Religion } \\
\hline Hindu religion & $193(48.9 \%)$ & $202(51.1 \%)$ & \multirow[t]{2}{*}{5.094} & \multirow[t]{2}{*}{0.025} \\
\hline Christian/Muslim & $63(38.4 \%)$ & $101(61.6 \%)$ & & \\
\hline \multicolumn{5}{|l|}{ Type of family } \\
\hline $\begin{array}{l}\text { Joint/three } \\
\text { generation/extended } \\
\text { nuclear family }\end{array}$ & $42(32.6 \%)$ & $87(67.4 \%)$ & \multirow[t]{2}{*}{11.839} & \multirow[t]{2}{*}{0.001} \\
\hline Nuclear family & $214(49.8 \%)$ & $216(52.7 \%$ & & \\
\hline \multicolumn{5}{|c|}{ Number of members in the family } \\
\hline$>4$ members & $101(38.5 \%)$ & $161(61.5 \%)$ & \multirow[t]{2}{*}{10.432} & \multirow[t]{2}{*}{0.02} \\
\hline$<4$ members & $155(52.2 \%)$ & $142(47.8 \%)$ & & \\
\hline \multicolumn{5}{|l|}{ Fathers occupation } \\
\hline fisherman/manual laborer & $167(49.9 \%)$ & $168(50.1 \%)$ & \multirow[t]{2}{*}{5.537} & \multirow[t]{2}{*}{0.002} \\
\hline All other occupation & $89(39.7 \%)$ & $135(60.3 \%$ & & \\
\hline \multicolumn{5}{|c|}{ Presence of chronic disease } \\
\hline Present & $3(12.5 \%)$ & $21(87.7 \%)$ & \multirow[t]{2}{*}{11.199} & \multirow[t]{2}{*}{0.001} \\
\hline Absent & $253(47.3 \%)$ & $282(52.7 \%)$ & & \\
\hline \multicolumn{5}{|l|}{ Influence of media } \\
\hline Present & $30(24 \%)$ & $95(76 \%)$ & \multirow[t]{2}{*}{30.81} & \multirow[t]{2}{*}{0.00} \\
\hline Absent & $226(52.1 \%)$ & $208(47.9 \%)$ & & \\
\hline
\end{tabular}

Thus Hindu religion, nuclear family, < 4 members in the family, father manual laborer or fisher man, absence of chronic disease, and absence of media influence on nutrition was found to be associated with undernutrition in the study participants.

When students $\mathrm{T}$ test was used to compare mean BMI in different group, significant difference in BMI was noted in the groups

01. Father fisherman / manual labourer and father having other occupation

02. Subjects who consume egg once a week and and those who consume less than that

03. Subjects with media influence on diet and those who do not

Table-2: Students $t$ test results with significant
Difference in mean BMI in the study subjects

\begin{tabular}{|c|c|c|c|}
\hline Variable & BMI & $t$ value & $p$ value \\
\hline \multicolumn{4}{|l|}{ Father occupation } \\
\hline fisherman/manual laborer & 18.5 & \multirow[t]{2}{*}{3.345} & \multirow[t]{2}{*}{0.001} \\
\hline All other occupation & 19.6 & & \\
\hline \multicolumn{4}{|l|}{ Consumption of egg } \\
\hline At least once a week & 19.61 & \multirow[t]{2}{*}{2.783} & \multirow[t]{2}{*}{0.006} \\
\hline Less than once a week & 18.69 & & \\
\hline \multicolumn{4}{|l|}{ Influence of media } \\
\hline Present & 21.5 & \multirow[t]{2}{*}{9.254} & \multirow[t]{2}{*}{0.00} \\
\hline Absent & 18.2 & & \\
\hline
\end{tabular}

Multivariate Analysis: Binary logistic regression was performed to analyze the factors predicting undernutrition in the study subjects. All variables with $p$ value less than 0.05 in bivariate analysis were considered as independent variables and undernutrition was taken as the dependent variable.

After doing binary logistic regression occupation of the father being manual labourer or fisherman was found to have adjusted odds ratio significant, with $95 \%$ confidence interval more than 1 and is found to be an independent predictor of undernutrition in female higher secondary children of Ambalappuzha block (model significance $p<0.001$ )

Table-3: Independent predictor of undernutrition in the study subjects after binary logistic regression

\begin{tabular}{|l|c|l|l|}
\hline \multicolumn{1}{|c|}{ Variable } & $\begin{array}{c}\mathrm{p} \\
\text { value }\end{array}$ & $\begin{array}{c}\text { Adjusted odds } \\
\text { ratio }\end{array}$ & $\begin{array}{c}95 \% \text { confidence } \\
\text { interval }\end{array}$ \\
\hline $\begin{array}{l}\text { Father fisherman /manual } \\
\text { labourer }\end{array}$ & 0.006 & 1.66 & $1.15-2.39$ \\
\hline
\end{tabular}

$\mathrm{R} 2=0.160$

Factors associated with under nutrition were Hindu religion, nuclear family, < 4 members in the family, father manual laborer or fisher man, absence of chronic disease, and absence of media influence on nutrition of which father being a manual laborer or fisherman was found to be an independent predictor of undernutrition.

\section{Discussion}

Prevalence of under nutrition: The prevalence of under nutrition in the female higher secondary students according to the present study taking Tim Cole anthropometric standards was found to be $45.8 \%$.

In National Family Health Survey-3 (2005-2006) the prevalence of under nutrition was $47 \%$ in girls aged 15-19 years taking cut-off point for BMI as 18.5 to 
Define thinness or acute undernutrition [8].

A rapid survey was conducted in Kerala by Ministry of Women and Child Development, Government of India with the technical support from UNICEF, India in the year 2013-2014 among adolescents aged 1518 years which showed that the prevalence of under nutrition in Kerala (BMI<18.5) was 42.6 in rural areas and 47.2 in urban areas [9].

A study on adolescents aged 15-17 years in a rural school in Thiruvanthapuram district; Kerala in 20132014 period, by Nazeema Beevi et al found that the prevalence of undernutrition among females in the above age group was $46.4 \%$ [10]. The prevalence of under nutrition in the present study was thus found to be similar to other studies conducted in the state and country

\section{Factors associated with under nutrition}

Religion: Our study found significant association between religion of the study participants and undernutrition. In the present study majority of the study participants were Hindus (70.6\%), second majority were Muslims (15.4\%) and Christians constituted the least number (14\%). Which was similar to NFHS 3 data where majority of people in Kerala belong to Hindu religion (59.5\%) second major religion being Muslim (23.1\%) and $17.1 \%$ Christians ( $0.3 \%$ constituted other religion) [11].

In 2012 a study was conducted by Dr. Ashok Kumar on adolescents in rural Tamil Nadu found that prevalence of undernutrition were common among the girls in Hindu community [12], which is similar to our study which shows association between Hindu religion and under nutrition.

Family characteristics: Our study found that there is significant association between undernutrition among adolescents and type of family (nuclear) and number of members in the family (less than 4). A community based study conducted by Amitava Pal in 2016 in West Bengal among 10 to 17 year old adolescents and its association with sociodemographic factors found positive association between underweight and nuclear family with number of members in the family $<4$ [13].

In our study majority of the study participants belonged to nuclear families $76.5 \%$ which is similar to NFHS 3 data which shows that majority of people in Kerala (54.8\%) belonged to nuclear families [11].

Our study also found significant association between occupation of the father (manual laborer or
Fisherman) and undernutrition among adolescents. $K$ Venkaiah et al conducted a study on rural adolescents in Varanasi in 2002 and found that families of laborers were significantly associated with underweight [14].

Ambalappuzha block, where the study was done mainly consists of poor families where majority of the men were semiskilled laborers (35.5\%) and women were housewives (78.7\%). A study by M.Z. Goldani in Brazil in 2013 showed that individuals whose fathers at the time of their birth were engaged in unskilled jobs or were unemployed were on average $1.18 \mathrm{~kg} / \mathrm{m} 2$ heavier than those whose fathers had non manual occupations when reach adolescence [15].

Our study also found significant difference in BMI between study participants whose fathers were manual laborer as compared to study participants whose fathers were involved in other occupation or of the study subjects

Chronic infection: Our study found significant association between absence of chronic infection and under nutrition but in a review by WHO on 'Malnutrition and Infection - A review - Nutrition policy discussion' in 1989, Andrew Tomkins and Fiona Watson describes about the malnutrition infection vicious cycle [16].

It describes about the mechanism of chronic disease causing undernutrition. In our study thyroid disease (hypothyroidism) was the most common chronic disease in the adolescents and hypothyroidism causes obesity than undernutrition [17]. In our study thyroid disorder was present in $1.4 \%$ of the study participants.

A college based study conducted by Kumaravel Velayudham et al in 7 colleges of Madhurai in Tamil Nadu in 2015 found that the prevalence of thyroid disorder among female college students aged 18-25 years was found to be $12.5 \% 18$. This difference might be due to the fact that the study was conducted in a coastal area of Kerala where fish /meat was consumed daily by $32.9 \%$ of the population and $80.9 \%$ of the population took fish / meat at least once a week.

Fish has high iodine content and can protect against thyroid diseases. The operational definition for chronic disease in the present study was taken as any disease reported by the study participant to have been present for more than 1 year. Thus thyroid disease that has been diagnosed within the 
Last one year was taken into account.

Influence of media: In the present study significant association was found between absence of media influence on dietary intake and undernutrition. Among the study participants $22.4 \%$ were influenced by media in taking decision regarding their nutrition.

In a study from Chennai done in the age group 11 to 17 years it was reported that, $82 \%$ buy food products and snacks based on advertisement, $42 \%$ follows diet and $42 \%$ exercise to get the body like their favorite media personality [19].

The low influence may be due the fact that most of the study subjects belonged to BPL families (54\%) where choice of food may not be available and Ambalappuzha being a coastal area the main food available is fish.

A qualitative study by Jinan C Banna et al on influences on eating among adolescents in a periurban area in Lima, Peru in 2015 describes the media influence on nutrition [20]. Jennifer. L. Harris in 2009 described the relationship between television viewing and unhealthy eating causing obesity [21].

A study in Malaysia among young adolescent (13to 15 years) by David S. Bickham in 2013 showed significant increase BMI in those who paid primary attention to media as compared to other activities like reading, sports etc [22] which is similar to our study which also showed significant difference in BMI among those who were influenced by media in taking decision regarding their diet and nutrition and those who were not.

Consumption of egg: Our study also showed significant difference in BMI among subjects who consume egg once a week and and those who consume less than that. In a study on 'The relationship between body mass index and lifestyle in a Brazilian adult population: a cross-sectional survey ' by Maria Rosárion in 2007 showed correlation between consumption of egg and mean BMI in women [23].

On multivariate analysis occupation of father of the study subjects (manual laborer or fisherman) was found be the only independent predictor of undernutrition among female higher secondary students in Ambalappuzha Block Panchayat. This is similar to the study by Amitava pal et al in 2015 which showed fathers occupation as an independent predictor of under nutrition [13].

\section{Conclusion}

Prevalence of under nutrition was found to be high among female higher secondary students in Ambalappuzha Block. Father being a manual laborer or fisherman was found to be an independent predictor of undernutrition.

\section{Reference}

01. UNICEF. Progress for Children- A report card on adolescents. Socio-demographic profile of adolescents. Number 10 April 2012 UNICEF, Figure: 2,1 Page 6.

[Crossref]

02. Adolescent Health Division, Ministry of Health and Family Welfare, Government of India. India_RKSK_Strategy Operational_Frameworktranslating strategy into programmes [Internet]. 2014.

[Crossref]

03. Govt of India. Planning Commission. Empowerment of women and development of children. 2001 [cited 2017 Jul 29]. Available from [Article] [Crossref]

04. Behrman J, Alderman $\mathrm{H}$, Hoddinott J. Hunger and malnutrition. Glob Crises Glob Solut. 2004;363-420.

[Crossref]

05. Hélène Delisle, $V$ chandramouli et al. Should Adolescents Be Specifically Targeted for Nutrition in Developing Countries?, To Address Which Problems, and How?. 2005 [cited 2017 Aug 3].

[Crossref]

06. WHO. Regional Office for the South-East Asia Region. Health Situation in the South-East Asia Region- 2001-2007. Geneva; Herndon: World Health Organization Stylus Publishing, LLC.

2009 [cited 2017 Nov 10]. Available from: [Article] [Crossref]

07. Ambalappuzha Block Panchayat, official website. [cited 2017 Oct 19]. Available from: [Article] [Crossref]

08. Parasuraman S, Kishor S, Singh SK, Vaidehi Y. A profile of youth in India. National Family Health Survey (NFHS-3), India, 2005-06. MumbaiInternational Institute for Population Sciences. 2009. [cited 2017 Mar 18]. Available from: [Article] [Crossref] 
09. Ministry of Women and Child Development, Government of India. Rapid survey on Children 2013-2014. [cited 2017 Jul 25].

Available from: [Article] [Crossref]

10. P NB, L M, Bindhu A. A study of adolescent health problems in a rural school in Thiruvanthapuram district, Kerala, India. Int J Community Med Public Health. 2016 Dec $21 ; 4(1) 100$.

[Crossref]

11. International Institute for Population Sciences, Deonar, Mumbai. National Family Health Survey (NFHS-3) India-2005-2006, Kerala. 2008 [cited 2017 Aug 9].

Available from: [Article] [Crossref]

12. Kumar A. Nutritional status of adolescent girls in rural Tamilnadu. Religion. 2012;102;42.

[Crossref]

13. Pal A, Pari AK, Sinha A, et al. Prevalence of undernutrition and associated factors- A crosssectional study among rural adolescents in West Bengal, India. Int J Pediatr Adolesc Med. 2017; Mar;4(1)9-18.

doi: [Article] [Crossref]

14. Venkaiah K, Damayanti K, Nayak MU, et al. Diet and nutritional status of rural adolescents in India. Eur J Clin Nutr. 2002 Nov;56(11)1119-25. doi: [Article] [Crossref]

15. Goldani MZ, Haeffner LS, Agranonik M, et al. Do early life factors influence body mass index in adolescents?. Braz J Med Biol Res. 2007;Sep;40(9)1231-6.

[Crossref]

16. Gillespie S, Mason J. Malnutrition and InfectionA review - Nutrition policy discussion paper No 5. UN-Adm Comm Coord-Sub comm Nutr ACCSCN. 1989;Oct;5.

[Crossref]

17. Laurberg $\mathrm{P}$, Knudsen $\mathrm{N}$, Andersen $\mathrm{S}$, et al. Thyroid function and obesity. Eur Thyroid $\mathrm{J}$. 2012 Oct; 1(3)159-67. doi: [Article] [Crossref]

18. Velayutham K, Selvan SS, Unnikrishnan AG. Prevalence of thyroid dysfunction among young females in a South Indian population. Indian J Endocrinol Metab. 2015 Nov-Dec;19(6)781-4. doi: [Article] [Crossref]
19. R Priyadarshini, Jasmine S Sundar, Valarmathi S, Kalpana S, Parameswari Srijayanth. Impact of media on the physical health of urban school children of age group 11-17yrs in Chennai - A cross sectional study. IOSR J Humanit Soc Sci. Volume 9, Issue 5 (Mar-Apr;2013)30-5. [Crossref]

20. Banna JC, Buchthal OV, Delormier T, CreedKanashiro HM, Penny ME. Influences on eatinga qualitative study of adolescents in a periurban area in Lima, Peru. BMC Public Health. 2016;Jan; $15 ; 16$.

Available from: [Article] [Crossref]

21. Harris JL, Bargh JA. Television viewing and unhealthy diet- implications for children and media interventions. Health Commun. 2009 Oct;24(7)660-73.

doi: [Article] [Crossref]

22. Bickham DS, Blood EA, Walls CE, et al. Characteristics of screen media use associated with higher BMI in young adolescents. Pediatrics. 2013 May;131(5)935-41. doi: [Article] [Crossref]

23. Peixoto Mdo R, Benício $M H$, Jardim PC. The relationship between body mass index and lifestyle in a Brazilian adult population- a crosssectional survey. Cad Saude Publica. 2007 Nov;23(11)2694-740.

[Crossref] 